\title{
Commentary \\ Rethinking Teaching of Basic Principles of Economics from a Sustainability Perspective
}

\author{
Namrata Chindarkar (i) and Dodo J. Thampapillai * \\ Lee Kuan Yew School of Public Policy, National University of Singapore, Singapore 259772, Singapore; \\ namrata.chindarkar@nus.edu.sg \\ * Correspondence: spptj@nus.edu.sg; Tel.: +65-6516-4844
}

Received: 1 April 2018; Accepted: 4 May 2018; Published: 9 May 2018

check for updates

\begin{abstract}
In this paper, we posit that sustainability warrants explicit recognition in the teaching of basic principles of economics. The conventional exposition of conceptual and analytic frameworks in basic principles in almost all standard economics textbooks overlooks at least two basic flaws. The first of these concerns the collection of residual externalities that exist without being internalized in market transactions and hence fall outside the calculus of national income accounting. For example, not all energy resource prices capture the entirety of the damages inflicted on natural ecosystems. The cumulus of residual externalities threatens the feasibility of sustainability. The second flaw is the absence of sustainability as a necessary condition in the fundamental benchmark of perfect competition (PC). Sustainability, when explicitly introduced in the PC benchmark, results in significant changes to conceptual premises in economics. The most significant of such changes concerns the axiomatic differentiation between "goods" and "bads".
\end{abstract}

Keywords: basic principles of economics; sustainability; residual externalities; perfect competition

\section{Introduction}

Sustainability is now the overarching theme that guides the attainment of an array of social objectives such as poverty alleviation, food security, and improved health. A comprehensive review of sustainability spanning a broad domain of connected themes can be found in Jenkins [1]. These themes include ecology, economics, society and culture, and religion. Central to the interconnectedness between the various facets of sustainability, is the recognition that economic growth and desired social outcomes have to be achieved within the limits of the earth's natural capital. Yet, when it comes to basic principles of economics, which form the foundation of economic thinking and policy making, there is only a tangential acknowledgment of these limits. Most economists, whilst not explicitly addressing the question of sustainability, assume that it would suffice to correct externalities as they emerge through appropriate price signals, incentives, and substitution effects. They further assume that loss of natural capital is remedial owing to the same mechanisms of price, incentives, and substitution [2]. In this paper, we call for the explicit treatment of sustainability in the basic principles. We propose revisions that would enable the basic axioms to truly capture intergenerational sustainability. Following Jenkins [1] and Costanza and Daly [3], we conceptualize such sustainability as the presence of total natural capital stock in excess of a threshold stock level across generations. This threshold level is determined by the biophysical attributes of the natural environment [4].

The conventional narrative of basic principles in almost all introductory textbooks in economics fails to show the lack of symmetry between the equilibria in various markets at the microeconomic level and the overall macroeconomic equilibrium in the economy. This imbalance emerges primarily because not all market externalities are fully internalized. Hence, residual externalities exist. Further, over time these residual externalities do accumulate. In this regard, indicators such as gross domestic 
product (GDP) and gross national income $(\mathrm{Y})$ do not readily capture the adverse effects of the residuals on economic performance. It is indeed true that basic principles illustrate the shortcomings of GDP. However, as explained subsequently, the microeconomic equilibrium, which serves as the basis for macroeconomic analysis, requires revision, especially to mitigate adverse policy responses. We also propose a revision to the benchmark of perfect competition (PC) in basic principles. This is because the efficiency of markets is premised on the conditions of PC without any recognition afforded to sustainability-a subject of considerable importance, especially in the contemporary context of climate change.

Contemporary texts on basic principles (for example: [5-10]) do not deal with the revisions that we propose in this paper. Without these revisions, sustainability and related issues may forever be relegated to the periphery of what is currently regarded as mainstream economics. This may in turn result in a misguided perception of policy challenges, resulting in inappropriate policy responses. The issue is serious because these introductory texts represent a cornerstone in a student's learning of economics. In a vein similar to that of the endowment effect described by behavioral economists like Knetsch [11] and Kahneman, et al. [12], it would be difficult to undo the learning accomplished from introductory texts. Some students, especially those pursuing a study in business or commerce, do not explore economics beyond the foundational modules. Even with students pursuing a major in economics, authors and instructors mistakenly assume that the issues we raise could be gleaned from later year modules. However, sustainability and related issues are covered in only some select modules on environmental economics, which are truly peripheral to the core economics curriculum. Hence, it is possible for students to graduate without ever having had exposure to issues concerning sustainability. Our proposal is that foundational material should include the revisions we suggest to mitigate the adverse effects of imperfect information.

Our perspective is that of instructors who deliver foundational content in economics to students, who increasingly believe that the basic principles outlined in introductory texts are far removed from reality. We begin our narrative with a synopsis of the benchmarks in basic principles. We then illustrate how and why the presence of residual externalities and their accumulation warrant revisions of the analytic frameworks that we introduce in foundational modules. Here, we provide illustrations of misguided perceptions and policies. Finally, we make a case for the benchmark of PC itself to be revised in recognition of the sustainability of markets.

\section{The Benchmarks in Basic Principles}

Several introductory texts, such as those mentioned above, navigate a student's journey into economics. The study of basic principles usually commences with the study of demand and supply leading to the establishment of markets. As indicated, the primary benchmark for the organization of markets is that of PC. The underlying drivers of demand and supply, when premised on the conditions of PC, deliver welfare maximizing outcomes for "goods" and "bads". Since "goods" are characterized by, more being preferred to less, their markets would expand. Given that "bads" are the direct opposite of "goods", the converse would unfold.

The basic principles texts also make clear the microeconomic foundation of macroeconomics. For example, see Mankiw's [13] (p. 44) clear narrative on "National Income: Where it Comes From and Where it Goes". The sum of all real (constant price) transactions in markets for goods and services provides the basis for Aggregate Demand (AD) or GDP, whilst the sum of such transactions in factor markets provides the basis for Aggregate Supply (AS) or Y. The status of prices in both types of markets (goods and services as well as factors) provides the basis for price level and inflation. The overall benchmark is one of "General Equilibrium", which portrays a macroeconomic equilibrium (GDP $\equiv \mathrm{Y}$ ) that rests on a myriad of perfectly competitive markets in equilibrium acting as supporting pillars alongside all leakages and injections being perfectly balanced. At a global level, the benchmark is a state of perfectly competitive (free) trade. Here, all nations display general equilibrium within their 
respective economies and engage in exchanges by recourse to their comparative advantages such that the trade balance of each nation is zero.

In contrast to the state depicted by the benchmarks, reality is one of gross imperfection (for example, see [14]). The purpose of the benchmarks in economics, at all levels, is to guide corrective policy intervention in the context of various imperfections that inevitably reduce the efficiency. Intervention often takes the form of institutional and regulatory measures alongside a set of incentives and disincentives. Examples of these include: deliberations by the World Trade Organization (at a global level), national tribunals (at a local level), and a system of market-based instruments such as taxes and subsidies (credits) applied both nationally and internationally.

Important questions that arise are: Is the current neglect of sustainability in basic principles texts tantamount to information asymmetry and moral hazard for a student learning economics? How can sustainability be explicitly brought into the discussion of axioms in basic principles? Moral hazard is often illustrated by recourse to "market for lemons" in second hand automobile sale yards. That is, although the seller knows which of the items for sale are defective, the buyer is unaware of them. Hence the condition of perfect information is violated and the welfare maximizing capability of perfect competition is compromised. In the study of economics, the seller is either the textbook author and/or the instructor and the buyer is the student. Moral hazard occurs because the seller (author) is content with omitting certain material even when he/she knows that such material is important. Information asymmetry emerges when the omission is deliberate, perhaps based on strong beliefs such as the irrelevance of sustainability considerations. We illustrate these below by recourse to two propositions.

\section{Proposition 1: Residual Externalities Need to Be Factored into the Definition of General Equilibrium}

To illustrate a basic flaw in the general equilibrium benchmark, consider how the collection of markets in perfectly competitive equilibrium at the microeconomic level is supposed to lend credence to equilibrium at the macroeconomic level. For illustrative purposes, consider the presence of environmental externalities that contaminate environmental sinks such as air sheds and lakes and rivers. In this instance, for the macroeconomic equilibrium $(\mathrm{GDP} \equiv \mathrm{Y})$ to hold, all externalities at the microeconomic level must have been fully internalized. Externalities are never fully internalized by neither regulation nor price intervention. For example, the various pollution protocols, as reviewed by Nordhaus [15], do not stipulate zero emissions or discharges into environmental sinks. Therefore, residual externalities invariably remain and, furthermore, do accumulate. These accumulated residual externalities are not captured in the macroeconomic equilibrium. Several examples validate the presence and accumulation of residual externalities. These include, amongst many others: the permanent and growing brown cloud in Asia (Ramanathan et al. [16]); fragmentation of polar icebergs (Bouhier et al. [17]); and the hole in the ozone layer (Fahey and Hegglin [18]). Hence, environmental economists deem that the definition of macroeconomic equilibrium should be revised to identify the disutility of residual externality (for example, see Thampapillai and Sinden [19]). That is $(\mathrm{GDP} \equiv \mathrm{Y}-\mathrm{DKN})$, where DKN represents a measure of the residual externality that remains. The tenet of this revision is that the policy maker mistakenly perceives the availability in the economy of an income equaling $Y$ that could be expended. But, in reality, the income that is available for spending is $\mathrm{Y}$ less the amount that has to be set aside safeguarding the environmental sink from the residual externality, namely DKN. Nevertheless, the reporting of national income accounting, worldwide, continues on the basis outlined in the System of National Accounts 2008 (for example, see [20]), namely, (GDP $\equiv \mathrm{Y})$. In practice, the estimates of GDP and Y are drawn, respectively, from the expenditure and income accounts. In most standard texts, the tradition of national income accounting and the approaches to macroeconomic policy are exposited on the basis of (GDP $\equiv \mathrm{Y}$ ). In essence, the economic performance of economies is overstated. Besides, the policies elicited on such premises, for example, strategies to further expand economic growth, are likely to exacerbate the overstatement. It should be noted, however, that the literature on environmental accounting attempts 
to define sustainable national income. Such definitions involve extending the revised equilibrium $(\mathrm{GDP} \equiv \mathrm{Y}-\mathrm{DKN})$ by incorporating various components such as additions to and withdrawals from stocks of nature, depreciation of manufactured capital, and efforts to mitigate environmental damage; for example, see Thampapillai and Sinden [19] and Todaro and Smith [21]. Further, given that some positive environmental externalities are also possible, DKN may be regarded as the net measure of residual externalities.

We illustrate the discrepancy between $(\mathrm{GDP} \equiv \mathrm{Y})$ and $(\mathrm{GDP} \equiv \mathrm{Y}-\mathrm{DKN})$ in Figure 1, with reference to the time paths of these two measures for China and India. In this illustration, spanning the period 1992-2015, we confine nature to the air-shed of the economy and measure DKN by the cost of mitigating total greenhouse gas emissions. The data and methodology employed for this illustration are presented in the supplementary material (Tables S1 and S2, and spreadsheet). As illustrated, the time paths of $Y$ and $(Y-D K N)$ display a clear divergence implying that mitigating damage to nature is a priority area for policy development. When the entirety of nature, that is, endowments such as soils, water, and forests, are considered, the divergence would be far more pronounced than that presented in Figure 1 and the priority for policy intervention would indeed be further enhanced. As illustrated in the supplementary material, the relationship between $\mathrm{Y}$ and DKN is indeed exponential. Knowledge of such an exponential relationship permits the identification of thresholds when DKN could exceed $Y$ and whereby the economy could lose its capacity to function; (for example see [19] (p. 127)).

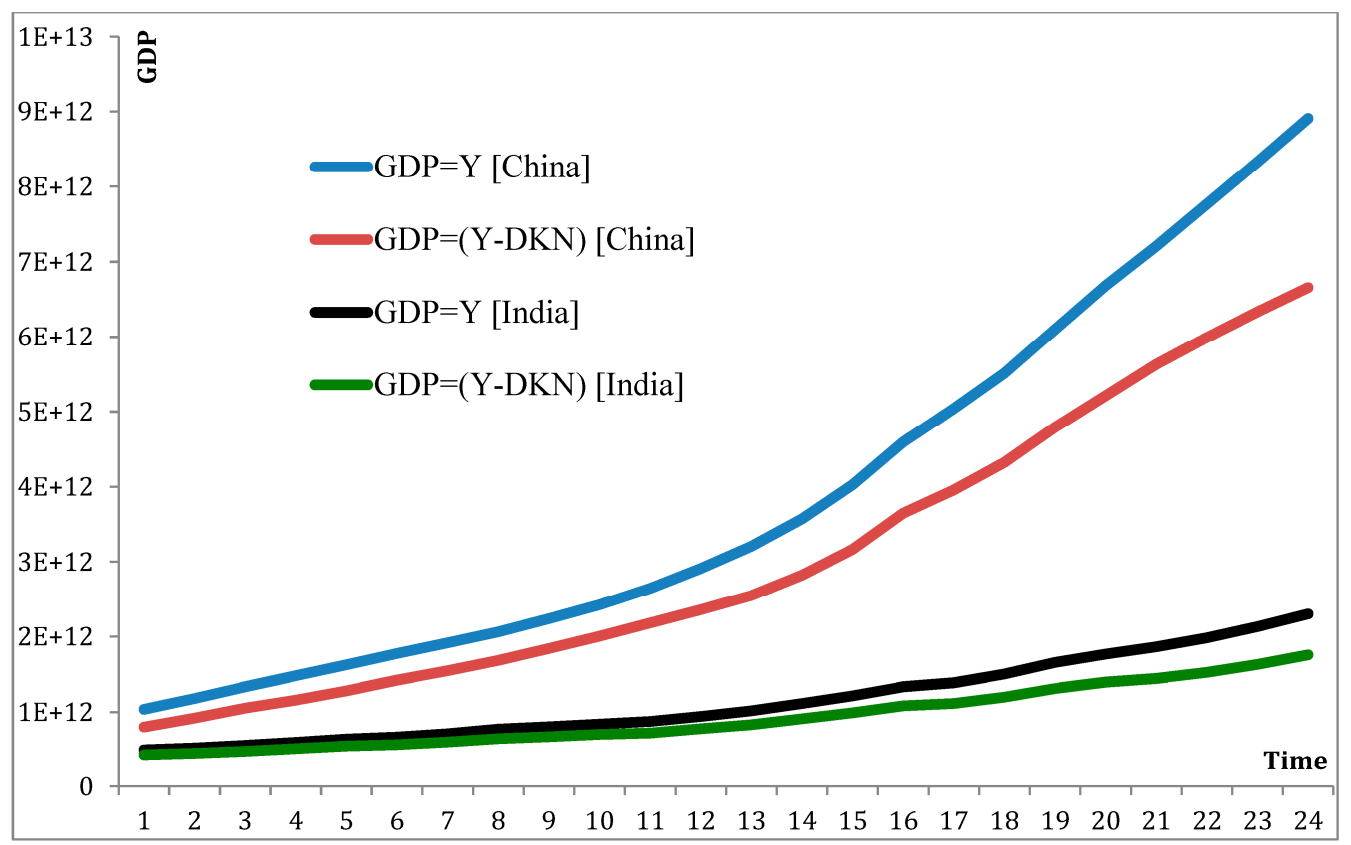

Figure 1. Time Paths of $\mathrm{Y}$ and (Y-DKN) for China and India.

Nevertheless, policymaking and narratives of their implication generally proceed on the basis of $(\mathrm{GDP} \equiv \mathrm{Y})$.

Consider now an extension of the abovementioned flaw in the realm of international trade. Mankiw [6] (p. 246) claims:

"Although natural resources can be important, they are not necessary for an economy to be highly productive in producing goods and services. Japan, for instance, is one of the richest countries in the world, despite having few natural resources. International Trade makes Japan's success possible. Japan imports many of the natural resources it needs, such as oil, and exports its manufactured goods to economies rich in natural resources." 
Had the system of national income accounting rested on the premise (GDP $\equiv \mathrm{Y}-\mathrm{DKN}$ ), then Mankiw's [6] claim is clearly an overstatement of Japan's economic performance. This is because Japan's accomplishment is also the export of environmental damage to the countries from which she has imported natural resources. Even if one would argue that the environmental damage could be internalized into the import price, the residual externalities and the long-term impacts of such externalities are hardly internalized. Recall that (DKN) represents a measure of the residual externality. A further difficulty with Mankiw's [6] narrative is the confinement of nature to extractable natural resources. Paradigms of sustainability, as exposited in [19,22-25], conceptualize nature as foundational capital encompassing a broad array of endowments including air, water, and soil. When this foundational capital is lost, then the economy ceases to function.

The cumulative effect of $(\mathrm{DKN})$ is indeed important. Concepts such the Environmental Kuznets Curve (EKC) advanced by Grossman and Krueger [26] and the various protocols for emissions reduction mentioned earlier do clearly overlook these cumulative effects. The EKC is based on the observation that marginal emission loads diminish as economic growth progresses and hence lends support to the principle of 'growth first and the environment later'. Even if economic growth occurs in compliance with the emission protocols, one has to note that the prime objective of these protocols is to reduce emissions and not eliminate them. Hence the growth of cumulative emission loads remains inevitable. Of the various texts that we reviewed, only one principles text, that of Case, et al. [27] (p. 364), appears to address the EKC and cumulative effects, as follows:

“... high levels of current emissions produce irreversible outcomes. Some would argue that by the time nations such as China and Vietnam develop enough to reduce their emissions, it will be too late. Many believe that global warming is such example."

The theory of comparative advantage is subject to similar flawed adaptation. The text (quoted in Enwegbara [28]) of a leaked memorandum from Lawrence Summers as chief economist of the World Bank reads:

"I think the economic logic behind dumping a load of toxic waste in the lowest-wage country is impeccable and we should face up to that ... I've always thought that under-populated countries in Africa are vastly under polluted."

The trade in toxic wastes had begun well before the infamous memo from Summers. As detailed in Okaru [29], in 1988 alone, West African countries had imported 24 million tons of toxic waste. Further, Okaru [29] provides a comprehensive list of violations and lack of care in the trade of hazardous toxic wastes. In the context of lax legislations, the notion of residual externalities is indeed meaningless. Such perversions of economic activity would be deemed unjustifiable had the basic analytic framework of national income accounting been revised to (GDP $\equiv \mathrm{Y}-\mathrm{DKN})$.

\section{Proposition 2: Sustainability Is a Necessary Condition in the PC Benchmark}

As indicated, the PC benchmark sits comfortably with the axiomatic differentiation between goods and bads. To reiterate, the differentiating characteristics of goods and bads are as follows:

Goods are those where more is preferred to less; and

Bads are those where less is preferred to more.

As illustrated in all contemporary basic principles texts, when all five conditions of PC, namely anonymity, homogeneity, perfect information, perfect mobility, and full employment, work together, the result is a unique market equilibrium configuration of quantity $\left(\mathrm{Q}^{*}\right)$ and price $\left(\mathrm{P}^{*}\right)$ that would maximize net social welfare. That is, any $(\mathrm{Q}, \mathrm{P}) \neq\left(\mathrm{Q}^{*}, \mathrm{P}^{*}\right)$ would yield a lower net welfare to society than that defined by $\left(\mathrm{Q}^{*}, \mathrm{P}^{*}\right)$. Behavioral economists question the validity of the welfare maximizing capability of market equilibrium. Amongst others, one reason is that the underlying drivers of markets, mainly utility functions, are determined by not only the items exchanged in markets, but also other 
attributes such as experienced utilities (for example see [30,31]). Nevertheless, even if such anomalies were corrected or deemed unwarranted in basic principles, the direct implication of the market equilibrium $\left(\mathrm{Q}^{*}, \mathrm{P}^{*}\right)$ that unfolds, when combined with the axioms, is that the bigger the market, the bigger the benefit to society. This observation further implies that economic growth through the expansion of markets for goods and the contraction (or better still elimination) of the markets for bads represent desirable outcomes. Note that the markets for emissions trading are in fact markets for bads with the intention of controlling and/or reducing the bads. However, in the presence of perverse incentives, the bads can accumulate in certain locations-especially poorer countries and regions-as discussed above.

One important reason for this discrepancy is that the benchmark of PC does not explicitly account for sustainability. A basic tenet in some versions of environmental economics is that sustainability of nature is a necessary condition for the sustainability of markets and economies. For example, Daly and Cobb [32], Victor [33], and Thampapillai and Sinden [19], exposit nature as foundational capital, on which the economy rests. Nature acts as a source providing basic resources and amenities, and also acts as a sink, being the receptacle for emissions and discharges. Given that market expansions would inevitably exert pressure on supporting natural endowments, managing without growth as Victor [33] suggests is not an undesirable option. Further, the term "sustainable economic growth", which some economists mistakenly use, is as explained by Daly [34] an impossible proposition. More recent examples of such tenuous propositions can be found in Gupta, et al. [35]. The primary basis for Daly's impossibility claim is the accumulation of residual emissions.

Thampapillai [36] and Thampapillai and Sinden [19] argue that the PC benchmark should be extended to include sustainability as the sixth explicit condition. Then, the role of time is explicit in the benchmark. In this context, one would adopt the optimization of an inter-temporal consumption function such as that illustrated by Dasgupta and Heal [37]. As a result, the criteria for the choice of markets would be those with a configuration of quantity and price that maximizes net benefits over an infinite time period. Despite the illustration being theoretical and abstract, the basic axioms of economics would change quite drastically. A good would be one where less is preferred to more, and a bad would be one where more is preferred to less.

\section{Conclusions}

In this paper, we advanced two propositions to rethink the teaching of basic principles of economics, namely, residual externalities must be factored in the definition of general equilibrium and the conditions of PC must be extended to include sustainability. Given that the cumulative damages caused by residual externalities and sustainability remain outside the scope of basic principles, students run the clear risk of encountering moral hazard and/or asymmetric information. The issue does not seem to be confined to basic principles. Specialized study of financial economics or trade economics, which attracts a fair number of students, also omits the issues that we have raised above. For example, consider Blinder's [38] exposition of the interconnectedness and complexity of financial markets. In articulating the risks associated with such markets, nature is not identified as an important element of the interconnectedness and a potential source of risk. Even within environmental economics, the fallacy persists. The exhaustive reviews of environmental economics by Cropper and Oates [39] and Stavins [40] failed to capture the linkages to macroeconomics. The treatment of macroeconomics and trade remains outside the coverage of most contemporary discussions in environmental economics.

Most important, perhaps, is for students of basic principles to appreciate the axiomatic change that unfolds, namely that smaller is better than bigger, when the basic benchmark is extended to include sustainability as an explicit condition.

Supplementary Materials: The following are available online at http:/ /www.mdpi.com/2071-1050/10/5/1486/ s1, Tables S1 and S2, Calculations illustrating the relationship between Y and DKN.

Author Contributions: Authors are alphabetically listed and have contributed equally to the work. 
Acknowledgments: We thank Kwan Chang Yee, Chen Jie, and participants at the Australian Conference of Economists (2017) for their helpful comments and suggestions. We thank the Lee Kuan Yew School of Public Policy for the financial support. Any errors are entirely those of the authors.

Conflicts of Interest: The authors declare no conflicts of interests.

\section{References}

1. Jenkins, W. The Spirit of Sustainability. In Berkshire Encyclopedia of Sustainability; Jenkins, W., Bauman, W., Eds.; Berkshire Publishing Group LLC: Great Barrington, MA, USA, 2010; Volume 1.

2. Toman, M.A. Economics and "Sustainability": Balancing Trade-Offs and Imperatives. Land Econ. 1994, 70, 399-413. [CrossRef]

3. Costanza, R.; Daly, H. Natural Capital and Sustainable Development. Conserv. Biol. 1992, 6, 37-46. [CrossRef]

4. Cleveland, C.J.; Ruth, M. When, Where, and by How Much do Biophysical Limits Constrain the Economic Process? A survey of Nicholas Georgescu-Roegen's Contribution to Ecological Economics. Ecol. Econ. 1997, 22, 203-223. [CrossRef]

5. Baumol, W.J.; Blinder, A.S. Economics: Principles and Policy, 11th ed.; Cengage: Mason, OH, USA, 2010.

6. Mankiw, N.G. Macroeconomics, 3rd ed.; Thomson South-Western: Mason, OH, USA, 2004.

7. Mankiw, N.G. Principles of Economics, 7th ed.; Cengage Learning: Stamford, CT, USA, 2014.

8. Frank, R.H.; Bernanke, B.S.; Lui, H.-K. Principles of Economics; McGrawHill Education: New York, NY, USA, 2015.

9. Hirshleifer, J.; Glazer, A.; Hirshleifer, D. Price Theory and Applications: Decisions, Markets and Information; Cambridge University Press: New York, NY, USA, 2005.

10. Parkin, M. Economics, 12th ed.; Pearson Education Limited: Harlow, UK, 2016.

11. Knetsch, J.L. The Endowment Effect and Evidence of Nonreversible Indifference Curves. Am. Econ. Rev. 1989, 79, 1277-1284.

12. Kahneman, D.; Knetsch, J.L.; Thaler, R.H. Anomalies: The Endowment Effect, Loss Aversion, and Status Quo Bias. J. Econ. Perspect. 1991, 5, 193-206. [CrossRef]

13. Mankiw, N.G. Macroeconomics, 6th ed.; Worth Publishers: New York, NY, USA, 2007.

14. Dixon, H.D.; Rankin, N. The New Macroeconomics: Imperfect Markets and Policy Effectiveness; Cambridge University Press: Cambridge, UK, 1995.

15. Nordhaus, W. Climate Clubs: Overcoming Free-riding in International Climate Policy. Am. Econ. Rev. 2015, 105, 1339-1370. [CrossRef]

16. Ramanathan, V.; Agrawal, M.; Akimoto, H.; Auffhammer, M.; Devotta, S.; Emberson, L.; Hasnain, S.I.; Iyngararasan, M.; Jayaraman, A.; Lawrence, M.; et al. Atmospheric Brown Clouds: Regional Assessment Report with Focus on Asia; United Nations Environment Program: Nairobi, Kenya, 2008.

17. Bouhier, N.; Tournadre, J.; Rémy, F.; Gourves-Cousin, R. Melting and Fragmentation Laws from the Evolution of Two Large Southern Ocean Icebergs. Cryosphere Discuss. 2017. [CrossRef]

18. Fahey, D.W.; Hegglin, M.I. Twenty Questions and Answers about the Ozone Layer: 2010 Update; World Meteorological Organization: Geneva, Switzerland, 2011.

19. Thampapillai, D.J.; Sinden, J.A. Environmental Economics: Concepts, Methods and Policies, 2nd ed.; Oxford University Press: Melbourne, Australia, 2013.

20. European Commission; International Monetary Fund; Organisation for Economic Co-operation and Development; United Nations. System of National Accounts; World Bank: New York, NY, USA, 2009.

21. Todaro, M.P.; Smith, S.C. Economic Development, 12th ed.; Pearson: Essex, UK, 2015.

22. Stiglitz, J.; Sen, A.; Fitoussi, J.-P. The Measurement of Economic Performance and Social Progress Revisited: Reflections and Overview; In Sciences Po: Paris, France, 2009.

23. Ayres, R.U. Sustainability Economics: Where Do We Stand? Ecol. Econ. 2008, 67, 281-310. [CrossRef]

24. Mearman, A.; Plumridge, A. Embedding Sustainability in the Economics Curriculum; University of the West of England: Bristol, UK, 2012.

25. Thampapillai, D.J. Environmental Economics: Concepts, Methods, and Policies; Oxford University Press: Melbourne, Australia, 2002.

26. Grossman, G.M.; Krueger, A.B. Economic Growth and the Environment. Q. J. Econ. 1995, 110, $353-377$. [CrossRef] 
27. Case, K.E.; Fair, R.C.; Oster, S.M. Principles of Macroeconomics, 11th ed.; Pearson Education Limited: Harlow, UK, 2014.

28. Enwegbara, B. Toxic Colonialism: Lawrence Summers and Let Africans Eat Pollution. Tech 2001, 121, 7-8.

29. Okaru, V.O. The Basel Convention: Controlling the Movement of Hazardous Wastes to Developing Countries. Fordham Environ. Law Rev. 2001, 4, 137-165.

30. Kahneman, D.; Wakker, P.; Sarin, R. Back to Bentham? Explorations of Experienced Utility. Q. J. Econ. 1997, 112, 375-405. [CrossRef]

31. Chindarkar, N. Why Public Policy Needs to Take a Broader View on Well-Being. In Governing Asia: Reflections on a Research Journey; World Scientific: Singpore, 2015.

32. Daly, H.E.; Cobb, J.B. For the Common Good: Redirecting the Economy towards Community, the Environment, and a Sustainable Future; Beacon Press: Boston, MA, USA, 1989.

33. Victor, P. Managing without Growth: Slower by Design, Not Disaster; Edward Elgar: Cheltenham, UK, 2008.

34. Daly, H.E. Sustainable Growth: An Impossibility Theorem. Development 1997, 40, 121-125.

35. Gupta, P.; Li, B.G.; Yu, J. From Natural Resource Boom to Sustainable Economic Growth: Lessons for Mongolia; International Monetary Fund: Washington, DC, USA, 2015.

36. Thampapillai, D.J. Perfect Competition and Sustainability: A Brief Note. Int. J. Soc. Econ. 2010, 37, 384-390. [CrossRef]

37. Dasgupta, P.; Heal, G.M. The Optimal Depletion of Exhaustible Resources. Rev. Econ. Stud. 1974, 41, 3-28. [CrossRef]

38. Blinder, A.S. Teaching Macro Principles after the Financial Crisis. J. Econ. Educ. 2010, 41, 385-390. [CrossRef]

39. Cropper, M.L.; Oates, W.E. Environmental Economics: A Survey. J. Econ. Lit. 1992, 30, 675-740.

40. Stavins, R. The Evolution of Environmental Economics: A View From the inside. Singap. Econ. Rev. 2017, 62, 251-274. [CrossRef]

(C) 2018 by the authors. Licensee MDPI, Basel, Switzerland. This article is an open access article distributed under the terms and conditions of the Creative Commons Attribution (CC BY) license (http:// creativecommons.org/licenses/by/4.0/). 